\title{
¿HACIA UNA CIBERPAIDEIA PARA AMÉRICA LATINA?*
}

\author{
Leonardo Tovar González \\ Universidad Santo Tomás
}

Recibido: enero 21 de 2005

Aprobado: abril 1 de 2005

\section{Resumen}

En diálogo crítico con las tesis sostenidas por Germán Vargas Guillén en su obra Filosofía, pedagogía y tecnología, el artículo examima las condiciones que la educación filosófica asume en nuestra "era de la información". Con la adopción de las mediaciones virtuales en la pedagogía de la filosofía, continuamos en nuestro tiempo el proyecto de enseñar a pensar con autonomía.

\section{Palabras clave}

Cibercultura, ciberpaideia, educación y filosofía, enseñanza de la filosofía, pedagogía, Germán Vargas Guillén

\section{Abstract}

In a critic dialogue with the thesis raised by German Vargas Guillén in his book Philosophy, Pedagogy and Technology, this article examines the conditions that the philosophic education asummes in our "era of the information". By adapting the virtual mediations in the philosophy's pedagogy, we continue with the project of teaching to think with authonomy in our era.

\footnotetext{
* Comunicación en el Coloquio Internacional Filosofía, Pedagogía y Enseñanza de la Filosofía, realizado por la Facultad de Humanidades de la Universidad Pedagógica Nacional y el Instituto de Filosofía de la Universidad de Antioquia, celebrado en Bogotá y Medellín, entre el 25 y el 29 de agosto de 2003.
} 


\section{Key words}

Cyberculture, Cyberpaideia, Education and Philosophy, Teaching of Philosophy, Pedagogy, German Vargas Guillén

Es muy cómodo ser menor de edad. Tengo un computador, que suple mi entendimiento; un programa de inteligencia artificial, que simula mi conciencia; internet $y$ multimedia, que cuidan mi dieta informativa, etc., de modo que no tengo que esforzarme. No tengo necesidad de pensar; si puedo pagar (o por lo menos piratear) las licencias, Bill Gates se encargará por mí de la enojosa tarea.

Con esta paráfrasis del archiconocido texto de Kant “Respuesta a la pregunta 'Qué es la Ilustración”, , deseo referirme de manera ex profeso provocativa a las tesis de Germán Vargas Guillén en su libro Filosofía, pedagogía y tecnología, y a partir de allí ofrecer algunas reflexiones sobre las relaciones entre filosofía y educación en nuestros tiempos ciberculturales ${ }^{1}$. Mostraré cómo, bajo el desacuerdo sobre los marcos de interpretación, prevalece un acuerdo de fondo sobre los fines educativos del quehacer filosófico.

El libro consta de diez capítulos, precedidos por los prólogos de las dos ediciones publicadas y seguidos de un apéndice. En la primera versión, editada por la Universidad San Buenaventura en 1999, el autor traza el hilo conductor de las investigaciones recopiladas con el lema de sabor heideggeriano "la caída de la pedagogía”, esto es, el descubrimiento de que no existe una epistemología de la pedagogía. En contra de las pretensiones del ochentista movimiento pedagógico en Colombia, orientado a delimitar el campo dis- ciplinar de la educación, se sostiene que ésta es una práctica que en lugar de criterios de validez, reclama condiciones de sentido. La fenomenología, comprendida esencialmente como reflexión encargada de reconciliar las múltiples experiencias humanas con el mundo de la vida, es el camino que emprende Vargas para reformular su proyecto en pos de una filosofía de la educación. La edición aumentada y corregida, lanzada en 2003, consolida esta propuesta, enfocada hacia la indagación por los problemas de la formación pedagógica en nuestra era informatizada.

En su doble sentido filosófico y pedagógico, las consideraciones del autor nos permiten, en primer lugar, superar el viejo prejuicio antipedagógico de un importante sector de nuestra filosofía académica, $y$, en segundo lugar, el recíproco prejuicio antifilosófico de algunos expertos de las ciencias educativas (por supuesto, la alianza entre el naciente Departamento de Filosofía de la Universidad Pedagógica y el consolidado Instituto de Filosofía de la Universidad de Antioquia, constituye un signo promisorio de que la mutua desconfianza puede superarse). Como se sabe, en Colombia las escuelas de formación universitaria en filosofía se dividen entre la filosofía pura y las licenciaturas en filosofía, es decir, entre los centros que se dedican al estudio de la tradición filosófica considerada por sí misma y las instituciones que preparan docentes de filosofía para la

1 Germán Vargas Guillén, Filosofía, pedagogía, tecnología: Investigaciones de epistemología de la pedagogía y filosofía de la educación, $2^{\text {a }}$ ed. (Bogotá: Alejandría Libros, 2003). 
educación media. A menudo, desde los primeros se ha considerado que en las últimas no se puede profundizar en la cosa filosófica misma porque sus integrantes deben enfatizar en lo pedagógico, entendido peyorativamente como mera didáctica instruccional. Contra la pretensión de los filósofos profesionales de que el dominio temático los califica por sí mismo para ejercer la docencia en filosofía, los voceros de las licenciaturas responden que existen aprendizajes específicamente pedagógicos que el profesor de filosofía requiere para su ejercicio profesional como educador. Lo más grave radica en que ambos bandos aciertan en sus mutuos cuestionamientos, pues, en efecto, los filósofos puros con frecuencia fracasan en su desempeño educativo en colegios y universidades, pero a la vez los licenciados se ahogan en ayudas educativas, incluidas las informáticas, a las cuales no saben qué aplicación filosófica darles.

En uno y otro caso, se olvida que la unión entre filosofía y educación, antes que asunto de conveniencia laboral, responde a una necesidad estructural. Desde los griegos, quien dice filosofía enuncia un proyecto de formación humana basado en la razón, y recíprocamente, quien dice educación, apela a una comprensión del hombre y de la realidad. Como sabemos, con el concepto de paideia se ha designado esta combinación indisoluble entre la búsqueda del logos del mundo y el cultivo del logos en los hombres, como bien nos lo enseña la mayéutica socrática. Y, atravesando los siglos, encontramos nuevas expresiones de esta génesis filosófica del educar y vocación educativa del filosofar, en las disputas medievales, en la ilustración moderna, en los juegos performativos posmodernos.
Sin embargo, la hiperespecialización de los discursos y metadiscursos educativos y filosóficos, ha llevado al olvido de sus nexos, o peor aún, a que estos se planteen como la subordinación de uno a otro. En consecuencia, estimo que también en la filosofía se debe emprender la reducción fenomenológica que ya se realizó con la pedagogía, y mostrar que también allí se configura una práctica que recibe su sentido del mundo de la vida. Si se quiere, se tratará de una práctica preeminente, ya que atañe al problema de la fundamentación conceptual de todas las otras prácticas, pero que en su carácter práxico sólo se realiza en articulación con la práctica educativa.

Cayetano Betancur, uno de los gestores de la normalización de la filosofía contemporánea en Colombia, ya postuló en los años cuarenta del siglo pasado esta correlación entre filosofar y educación al hablar de "la filosofía como paideia"'. Con base en un análisis de tipo fenomenológico, el autor antioqueño destacó la función pedagógica consustancial a la filosofía: "Floración y finalidad de toda filosofía -citaba Betancur de Dilthey- es Pedagogía en su sentido más amplio: teoría de la formación del hombre”.

La comprensión asimismo fenomenológica de Germán Vargas coincide reiteradamente con este aserto: "Quiero volver sobre la idea de que el tema fundamental de la pedagogía es la formación” ${ }^{3}$. Sin embargo, los interrogantes que ofrece la formación (la realización de la persona, las relaciones con el mundo natural y cultural, las relaciones intersubjetivas, etc.) no pueden ser asumidos del mismo modo que lo hiciera Betancur cincuenta años atrás, ni, menos, los griegos dos milenios y medio antes.

\footnotetext{
Cf. Cayetano Betancur, “La filosofía como paideia”, Revista de Indias (Bogotá) 97 (1947): 17- 49.
} Vargas Guillén, Filosofía ..., 279. 
Las características de nuestra época, dominada por el disponer tecnológico que depuso la presencialidad del ser antiguo, la aparición del Dios cristiano y la representación modernas, exigen una nueva mirada filosófica sobre la práctica educativa. En el campo pedagógico, Germán Vargas se propone realizar para nuestra era informatizada la ontología del presente que, según Foucault, Kant inauguró con su ensayo sobre la Ilustración ${ }^{4}$. Desde luego, no se trata de un mero truco de sustitución mediante el cual allí donde antes se hablaba de libros, imprentas y lectores, hoy se ponga hipertextos, multimedia e interfaces. No sólo han cambiado los objetos, sino también las condiciones de comprensión, y por ello el proyecto filosóficopedagógico de formación exige nuevos marcos interpretativos.

Inspirado en Heidegger y apoyado en las investigaciones en inteligencia artificial, nuestro autor considera que se debe renunciar al proyecto moderno centrado en el sujeto entendido como héroe del relato, y abrirse a la polifonía de la construcción plural de sentido que se abre en la apropiación de los dispositivos cibernéticos que configuran el mundo de la vida contemporáneo. Contra la subjetivación solipsista moderna, se impone la desubjetivación, pues ¿quién es el autor de un CD de multimedia, quién habla en Internet, quién es el enunciador de un hipertexto?

El sujeto se pierde, pero se ganan los sujetos, en tanto se comprende con Husserl que, gracias al lenguaje, las relaciones intersubjetivas constituyen en cada caso lo que somos cada uno de nosotros. En clave ética y política, ello exige realizar una democracia comunicativa donde, lejos de la jerarquización propia del Estado moderno, los ciudadanos se comprendan solidariamente como copartícipes del bien público. En clave cultural, no se trata de plegarse acríticamente a la cibertecnología, sino de asumirla a profundidad para valernos de ella en las búsquedas plurales de nuestras identidades como colombianos y latinoamericanos.

Tal vez ciberpaideia no sea el apelativo más afortunado para designar este propósito de Germán Vargas de pensar, a la altura de nuestro tiempo y para nuestro contexto, filosóficamente la pedagogía y pedagógicamente la filosofía, pero con él espero haber sintetizado mi comprensión sobre su proyecto. Por lo demás, creo que él y Foucault, antes que un abandono de la empresa kantiana de comprensión del presente, lo que han hecho es reajustarlo para nuestro tiempo, pues, como reveló Adorno, educativa, política y filosóficamente, el sapere aude continúa teniendo validez:

'La ilustración es la salida del hombre de su minoría de edad autoculpable'. Considero que este programa de Kant (...) sigue estando hoy sumamente vigente. La democracia descansa sobre la formación de la voluntad de cada individuo particular, tal como se sintetiza en la institución de la elección representativa. Para que de ello no resulte la sinrazón, hay que dar por supuestos el valor y la capacidad de cada uno de servirse de su entendimiento ${ }^{5}$.

4 Cf. Michel Foucault, “¿Qué es la Ilustración?” (1983), Estética, ética, hermenéutica, trad. Ángel Gabilondo (Barcelona: Paidós, 1999) 335- 352.

5 Theodor Adorno, “Educación para la emancipación”, Educación para la emancipación, trad. Jacobo Muñoz (Madrid: Morata, 1998) 115. (Original alemán, "Erziehung zur Mündigkeit”). Conversación con Hellmut Becker, emitida en la radio de Hesse el 13 de agosto de 1969. 
Treinta años después, frente a las relaciones entre filosofía, educación y tecnología, posiblemente también debamos aplicar la reconstrucción fenomenológico-comunicativa emprendida por Jürgen Habermas, y abandonar la crítica negativa a ultranza enarbolada por los viejos frankfurtianos. La sospecha radical sobre los efectos domesticadores de los aparatos cibernéticos que irónicamente dejé traslucir en mi epígrafe kantiano, puede y debe ser reemplazada por la comprensión afirmativa de las transformaciones de la educación en la era de la informatización, siempre y cuando ésta recoja desde dentro los postulados emancipadores de una filosofía crítica. También con I.A., con multimedia, con Internet, la exigencia fundamental de nuestra educación se patentiza en el adorniano “Que Auschwitz no se repita”, lo que en traducción latinoamericana significa que las desapariciones de los presos políticos no se repitan, que las ejecuciones sumarias no se repitan, que el terror terrorista y antiterrorista no se repita. Para el específico caso colombiano, la repetición a diferentes escalas de la toma y contratoma del Palacio de Justicia en noviembre de 1985, de las masacres respectivamente paramilitar y contramilitar de Mapiripán (julio de 1997) y Bojayá (mayo de 2002), de las múltiples y ominosas manifestaciones de violencia doméstica y social, revela que la educación entre nosotros, empezando por la educación filosófica, ha fracasado.

Con Adorno, no ignoramos las condiciones objetivas que han servido de caldo de cultivo de la barbarie, porque detrás de cada genocida, sea cual sea la causa que dice defender, existe una historia de exclusión que debemos afrontar, no para exonerar su culpa moral y jurídica, sino para asumir nuestra responsabilidad en la búsqueda de un mundo mejor. Como educadores y filósofos, ésta se concentra en el programa de una pedagogía crítica que dialógicamente concientice sobre la injusticia, postule ideales emancipatorios y prepare mediaciones para el cambio social. La apelación a una teoría crítica de la educación con Paulo Freire a la cabeza, es una referencia insoslayable en este compromiso transformador.

En este proyecto sí se requieren más computadores en las escuelas, pero no para engrosar el inventario de activos fijos, sino para generar nuevas competencias cognitivas en los educandos y, cómo no, en los educadores. También se necesita más multimedia, pero no para jugar en vez de aprender, sino para aprender a través de los juegos interactivos creados por los mismos estudiantes. Y más Internet, pero no para que en una autocomplaciente minoría de edad se bajen trabajos que se entregan como propios a los profesores, sino para que todos los sujetos educativos nos conectemos con la pluralidad de saberes y culturas.

De cara a la educación ética y política, la ciberpaideia debe contribuir hoy también a derrocar el orden autoritario (y su hermano gemelo, el anarquismo ligero) de nuestra sociedad, en aras de una democracia construida desde el cultivo de la libertad. Como señalaba Adorno, "La única fuerza verdadera contra el principio de Auschwitz sería la autonomía, si se me permite valerme de la expresión kantiana: la fuerza de reflexionar, de autodeterminarse"6. De nuevo, se trata de formar a los sujetos contra las morales gregarias que los hace plegarse de manera con-

\footnotetext{
6 Theodor Adorno, “Educación después de Auschwitz”, Educación para la emancipación, trad. Jacobo Muñoz (Madrid: Morata, 1998) 83. (Original alemán, “Erziehung zur Mündigkeit”). Conferencia en la radio en la radio de Hesse, emitida el 18 de abril de 1966.
} 
formista a los grupos, así estos en nuestra “era de la información” se disloquen alrededor del planeta en los inabarcables nodos de la red mundial.

El mismo Adorno era consciente de que combatir la apropiación contemporánea de la técnica equivalía “...a algo así como ir en contravía del espíritu del mundo" ella se halla enraizada en la tendencia de la civilización mundial. Ocho lustros después, podríamos agregar que sus prevenciones tal vez se justificaban frente a una técnica por así decirlo rígida y masiva, pero no en relación con la tecnología flexible e individual (pret-a-porter) del siglo XXI. Y, sin embar- go, no podemos eludir el "velo tecnológico” que día a día nos cubre más. Por mencionar un solo ejemplo, en nuestra informatizada sociedad de consumo, el sentido estético de algunos jóvenes parece agotarse en el diseño de los teléfonos celulares, sin que ni siquiera se den en muchos casos los correspondientes aprendizajes tecnológicos.

En síntesis, la ciberpaideia es poner en juego para nuestro tiempo la educación para la emancipación inspirada por Kant. Reeducar críticamente la filosofía, hacer virtuosa antes que virtualizar la educación, democratizar la democracia, siguen siendo ejercicios de Ilustración.

7 Adorno, “Educación ...”, 89. 